\title{
La filosofía política en su laberinto*
}

* Anchustegi, Esteban, El tiempo de la filosofia politica, Lima, Editora Jurídica Grijley, 2013. Tra-Melaua, revista de Ciencias Sociales. Facultad de Derecho y Ciencias Sociales. Benemérita Universidad Autónoma de Puebla, México / IssN: 1870-6916 / Nueva Época, Año 8, № 37, octubre 2014 / marzo 2015, pp. 214-219. 
Fernando Golvano Gutiérrez*

La crisis de la teoría política de orientación positivista, los desafíos actuales de Estado del bienestar y su declive en la Europa que lo creó, los procesos emergentes de signo social y descolonizador desde finales de los años sesenta, las turbulencias que afectan a la economía política del mundo global, los retos del proyecto democrático, la emergencia de nuevos sujetos políticos que amplían, con otras subjetividades plurales, el espacio público-democrático, que renuevan la noción de ciudadanía y comunidad, contribuyen a un renovado interés por la filosofía política. Le otorgan un valor intempestivo.

En este contexto, adquiere un valor oportuno la publicación de Esteban Anchustegi, El tiempo de la filosofia política (Editora Jurídica Grijley, Lima, 2013), que, a modo de manual descriptivo y analítico, permite divulgar una aproximación contemporánea a la filosofía política. Su autor es profesor de Filosofía Moral y Política en la Universidad del País Vasco, y docente en diversos másteres y posgrados en universidades españolas y latinoamericanas. Simultáneamente, ha sido editor de la obra Economía, democracia y valores en un mundo global (Plaza y Valdés, 2013). Además, ha publicado numerosos artículos sobre cuestiones como ciudadanía, democracia, nacionalismo y lealtades políticas, desde un enfoque que ha transitado de los márgenes de un marxismo crítico, en los años ochenta y noventa, hacia posiciones actuales más propias del republicanismo cívico y del racionalismo pragmático habermasiano.

En la obra que reseñamos, Anchustegui despliega una indagación sintética sobre varios nudos. En primer lugar, expone las controversias relativas a las lábiles y porosas fronteras disciplinares y a sus relaciones con la filosofia moral. Dado que la reflexión y la praxis política están imbricadas desde sus orígenes, la interrogación filosófica tiene como fundamentos la política y la moral, pero sin referencia trascendente a ninguna teoría del bien o del deber. Su ámbito no puede olvidar el imperativo aristotélico del dar cuenta y razón sin determinaciones heterónomas. La isonomía, la autonomía y la institución del mundo de vida en común se fundan en el hacer reflexivo y práctico, evitando dos tentaciones: sea la del moralismo abstracto e idealista, sea la del olvido de las dimensiones morales que conciernen a la filosofía política.

\footnotetext{
* Profesor de Filosofía Política en el Departamento de Filosofía de los Valores y Antropología Social de la Universidad del País Vasco, España. (fernando.golvano@ehu.es)
} 
Dar forma a sus objetos y tareas específicas, evitando esas tentaciones fatales - y otras derivas, como su reducción a un mero saber experto de signo managerial al servicio de la gobernanza-, forma parte del estatuto complejo de esa disciplina que consiste, como postulara Leo Strauss en su célebre ensayo "¿Qué es filosofía política?” (1968), "en el intento de adquirir conocimientos ciertos sobre la esencia de lo político y sobre el buen orden político o el orden político justo". ${ }^{1}$ Ese telos propio de la filosofía política es actualizado por Anchustegui en la perspectiva de "una racionalidad específica del discurso filosófico-político, tarea para la cual puede ser útil la propuesta habermasiana que considera prioritario el desarrollo de la acción comunicativa, orientada al entendimiento intersubjetivo, frente al monopolio de la acción instrumental o estratégica, diseñada respecto a fines y orientada al éxito". Tales son las premisas que presiden su elucidación en este ensayo.

En segundo lugar, impugna el enfoque neopositivista, hegemónico en la tradición anglosajona, que restringe el ámbito de la disciplina a una especie de metaciencia política sin consecuencias descriptivas, críticas y evaluativas. Sostiene que la filosofía política, paradójicamente, debe trazar y, al mismo tiempo, neutralizar sus fronteras con la ciencia política y reivindicar el enfoque de Parekh, en su artículo "Algunas reflexiones sobre la filosofía política contemporánea", ${ }^{2}$ a saber, que la misma debe armonizar su doble objeto: como disciplina moral y normativa (indagar en los valores que orientan el discurso y la acción política obliga a una reflexión sobre la dimensión moral de la filosofía política que no ha dejado de estar presente en modos y enfoques diferentes) y como disciplina analítico-descriptiva (la reflexión sobre los conceptos y categorías en el marco de su propia historia y en su conexión con las ciencias sociales y políticas tal y como se han desarrollado en su devenir social-histórico). No obstante, la dificultad de esa tarea reside en el complejo entrelazamiento de esas dos funciones en cada contexto social e histórico, y en diálogo con la ciencia política.

En tercer lugar, describe los principales modelos históricos que han tomado forma en el devenir de la filosofía política. Esboza un mapa sintético de las tradiciones clásicas y modernas, y prosigue su descripción, de un modo somero, en la revitalización de la filosofía política como filosofía práctica en los años setenta y ochenta. Concluye su primera parte con la exposición de los retos y tareas actuales de la disciplina; los agrupa en tres ámbitos: 1) Recuperar la dignidad de la actividad política, ofreciendo una respuesta teórica a la crisis de la legitimación democrática; 2) Hacer frente

\footnotetext{
${ }^{1}$ Strauss, Leo, ¿Qué es filosofía política? Madrid, Guadarrama, 1968, p. 14.

${ }^{2}$ Parekr, Bhikhu, "Algunas reflexiones sobre la filosofía política contemporánea", La política: Revista de estudios sobre el estado y la sociedad, núm. 1, Barcelona, Paidós, 1996, pp. 5-22.
} 
a los peligros que acechan a la democracia tanto en el nivel estatal como en el internacional; y 3) Reflexionar sobre las conflictivas relaciones entre mercado y democracia, o sobre los efectos de la cultura de masas, los desafíos de la ecología, la cuestión de la justicia planetaria y los imperativos kantianos. Tales retos requieren de la refundación permanente del proyecto democrático en su doble anclaje, nacional e internacional, para lo cual la empresa teorética resulta insuficiente si no converge con un movimiento real en el hacer del demos crecientemente heterogéneo en el seno de cada sociedad y en su manifestación internacional.

La segunda parte se centra en el dominio de lo político y la acción política. Se focaliza en una valoración crítica de la disciplina en torno al poder político y su legitimación, la democracia como régimen en permanente construcción, y la definición del espacio público. Hubiera sido conveniente un desarrollo más pormenorizado y polémico de esas cuestiones y, de manera específica, sobre las nuevas figuras de la hybris política que se relacionan con la "parte oscura" de la política, y que amenazan el devenir de la democracia, eso que Castoriadis denomina, en Figuras de lo pensable, la condición trágica de la democracia. ${ }^{3}$ Será en la tercera parte de la obra donde despliegue un mayor desarrollo crítico de cuestiones como la comunidad política y la ciudadanía, las identidades nacionales, ciudadanía y derechos sociales, multiculturalismo y lo relativo a la lealtad política. Esta última cuestión es abordada en su genealogía histórica, citando como casos ejemplares las posiciones de Sócrates, Aristóteles, Cicerón, Maquiavelo y Hegel, y en relación con los modelos de comunidad política (liberal, comunitarista y cívica o republicana) y a sus atributos principales.

La controversia en torno a esa cuestión y su asociación con el debate de la ciudadanía y el proyecto de la configuración democrática, dada su pertinente actualidad, hubiera merecido un desarrollo mayor que el enunciado en este ensayo. La perspectiva elegida para abordarlas, como ya se ha comentado, es el modelo republicano, entendido como una expresión de la identidad cívica en la concepción de un orden democrático. Anchustegui sostienen que, frente a la propia crisis de legitimación de la democracia y de la política en general, el republicanismo permite ahondar en la virtud cívica, fundamentada en la ley democrática, que permite y consolida la diferencia, el respeto a lo particular y la convivencia tolerante y pacífica en la diversidad.

En este enfoque se aproxima a las tesis de Chantal Mouffe, quien, en El retorno de lo político, postula "que el ideal de ciudadanía podría contribuir enormemente a la extensión de los principios de libertad e igualdad. Combinando el ideal de derechos y pluralismo y las ideas de inspiración pública

${ }^{3}$ Castoriadis, Cornelius, Figuras de lo pensable, Cátedra-Universitat de Valencia, 1999, p. 147. 
y preocupación ético-política, una nueva concepción democrática de ciudadanía podría restaurar la dignidad a lo político y proporcionar el vehículo de la construcción de una hegemonía democrática radical". ${ }^{4}$

Esta obra es una herramienta útil para estudiantes universitarios de filosofía, ciencias políticas, sociología, agentes sociales y ciudadanos comprometidos con un ideal democrático que requiere de creaciones y lealtades renovadas. Anchustegui sostiene que esa dimensión moral no debiera ir más allá de la definición de principios y valores que permitan fundar una ética pública o mínima, tal y como lo postulan autores como Heller, Camps o Cortina. En relación con la necesaria distinción entre la filosofía política y la ciencia política, reconoce que existen fronteras híbridas y cambiantes; no obstante, reivindica la posibilidad de "una teoría política que sea una filosofia política, sin que por ello tenga que situarse en el terreno "ideológico" de las preferencias subjetivas no argumentables". Con buen criterio, se apoya en las tesis de Strauss para afirmar la pertinente primacía de la filosofía política, dado que despliega un enfoque más radical y englobante que la ciencia correspondiente, al tiempo que permite ser ponderada por una reflexión ética y moral.

La claridad expositiva y la metodología utilizada por el autor, con breves introducciones sobre la genealogía de algunas cuestiones, además de la magnífica compilación de referencias bibliográficas, convierten este ensayo en una guía cabal para comprender los desafíos actuales de la filosofía política. Con todo, hubiera sido pertinente una mayor atención sobre la actualidad de la reflexión de esta disciplina en relación con los desafíos del régimen democrático en los contextos socio-históricos específicos y en el devenir glocal. El malestar de la filosofía política en nuestra época presente está íntimamente vinculado al malestar democrático que denuncia Pierre Rosanvallon en La légitimité démocratique, ${ }^{5}$ cuyos síntomas identifica en las amenazadoras derivas de la antipolítica y la despolitización.

La filosofía política, en el laberinto de su función y actualización, debe recuperar su dimensión crítica para crear nuevas figuras de lo pensable y de lo realizable en el horizonte de un proyecto democrático siempre en construcción, como la herencia de la Ilustración moderna. Dado que no hay episteme ni filosofía política que dicte principios o normas de modo absoluto, queda el hacer crítico de una filosofía política que contribuya a una doxa reflexionada y a la impugnación permanente de la racionalidad instrumental y científicotécnica que gobierna soberana en la naturaleza y la sociedad. Asimismo, la filosofía política, como saber experto y currículum disciplinar, ha olvidado a

\footnotetext{
${ }^{4}$ Chantal Mouffe, El retorno de lo político. Comunidad, ciudadanía, pluralismo, democracia radical, Barcelona, Paidós, 1999, p. 105.

${ }^{5}$ Rosanvallon, Pierre, La legitimidad democrática, Madrid, Paidós, 2010.
} 
menudo que su cometido tiene dimensiones prácticas en cuanto se integra o participa en el flujo colectivo, reflexivo y lúcido que instituye o transforma las instituciones, y desborda el marco nacional.

Asimismo, se agradece el apartado específico sobre la aportación de una filosofía de la subjetividad que atiende a la irrupción de nuevos sujetos y enfoques que amplían los dominios convencionales de la filosofía política, como la aportación del feminismo, presente ya en otros célebres manuales como el de Will Kymlicka (Filosofia política contemporánea. Una introducción, 1990) o el de Jonathan Wolff (Filosofia política. Una introducción, 1996). Tal vez en nuevas ediciones o en otras publicaciones este autor incorpore una elucidación sobre esas y otras cuestiones que recrean galerías nuevas de reflexión en un laberinto que le es propio y del cual no logrará salir. 